\title{
Anti-DNA Antibody
}

National Cancer Institute

\section{Source}

National Cancer Institute. Anti-DNA Antibody. NCI Thesaurus. Code C1580.

An antinuclear autoantibody directed against nuclear DNA. 